\title{
INFLUENCE OF SELECTED FACTORS ON CPA LICENSURE EXAMINATION RESULTS
}

\author{
Carmen C. Herrero \\ Faculty member in Accountancy, College of Business, Rizal Technological University, \\ Mandaluyong City, Philippines \\ E-mail address: ddircarmenherrero111@gmail.com
}

\begin{abstract}
Keywords: CPA Examination performance, Course interventions, Attribution theory, Documentary analysis
\end{abstract}

\begin{abstract}
The researcher looked into the factors that affected the performance of Rizal Technological University CPA board examinees on the 2012 licensure examinations to determine the intervention necessary to improve the university's review programs. Descriptive research design was used wherein twenty-four Bachelor of Science in Accountancy graduates who took the May and October 2012 board examinations were surveyed using a validated researcher-made questionnaire. Documentary analysis was used for evaluating qualitative data. Results revealed that: student factors (interest in the accounting program, time spent for studying lessons and availing of library/internet resources in research activities) and home/family factors (family financial support, parental involvement in studies, motivation and encouragement) highly influence performance; school factors (adequacy of relevant library books and materials, adequacy of technology hardware and software, good accounting program and good accounting faculty) were perceived to have average influence; and scholarships, grade weighted averages and attendance to review courses handled by prestigious review schools were found to be positive factors in passing the board examinations. Based on the findings, the researcher recommended that the regular assessment through qualifying examinations be conducted and that the pre-board/mock examinations in the review classes be strengthened.
\end{abstract}

\section{INTRODUCTION}

Each year thousands of candidates sit for the Certified Public Accountant (CPA) licensure examination in the Philippines. The passing statistics is only about 20 percent of first-time candidates (Bala, 2008). According to Abrugar (2009) many critics say that it is one of the most difficult professional board examinations in the country. The difficulty of passing the CPA board examination is reflected in the relatively low passing rates both in local and national levels. In the Rizal Technological University (RTU), the CPA results have not been consistent. In some cases, the results were higher than the national percentage. In some instances however, they were lower (RTU Annual Reports, 2011-2014). With these trends, it is imperative that innovative and continuous intervention programs be undertaken in order to improve the RTU accounting graduates' performance in CPA board examination. This intervention program must be research-based hence, this research.

This study was anchored on the attribution theories advanced by Heider as cited by Hunt (2009), Jones and Davis (2005), and Kelly's (2007) covariance model. Heider's theory is the assertion that man perceives events of critical importance for the interpretation of human work. Such causes could be traced to factors located within the person and those that are drawn from the environment of the person. The two main ideas put forward by Heider became influential: "1) When we explain the behavior of others we look for enduring internal attributions, such as personality traits. For example, we attribute the behavior of a person to their naivety or reliability or jealousy; and 2) When we try our own behavior we tend to make external attributions, such as situational or environment". 
Jones and Davis Correspondent Inference Theory helps in the understanding process of making an internal attribution. They say that a person tends to do things when they see a correspondence between motive and behavior. Dispositional (i.e. internal) attributions provide information from which a prediction could be made about a person's behavior. The Theory describes the conditions under which people make dispositional attributes to behavior they perceive as intentional. Jones and Davis used term correspondent inference to refer to an occasion when an observer infers that a person's behavior matches or corresponds with their personality. The theory says that a people draw from five sources of information: 1) Choice: If a behavior is freely chosen it is believed to be due to internal (dispositional) factors; 2) Accidental vs. Intentional Behavior: Behavior that is intentional is likely to be attributed to the person's personality and behavior which is accidental is likely to be attributed to situation/external causes; 3) Social Desirability: Behaviors low in social desirability (not conforming) lead a person to make (internal) dispositional inferences more than socially undesirable behaviors; 4) Non-Common Effects: if the other person's behavior has important consequences 5) Hedonistic Relevance: If the other person's behavior appears to be directly intended to benefit or harm others, it is assumed that it is "personal," and not just by-product of the situation both are in.

In Kelly's (2007) covariance model, it is advocated that a particular activity should be attributed to some characteristics (internal) of the person or the environment (external). The term covariance simply means that a person has information from multiple observations, of different times and situations, and can perceive the covariance of an observed effect and its causes. Kelly argues that in trying to discover the causes of behavior people act like scientists. More specifically, they take into account three kinds of evidence. He believes that are three types of causal information which influence one's judgments. Law factors = dispositional (internal attributions): 1) Consensus: the extent to which other people behave in the same way in a similar situation; 2) Distinctiveness: the extent to which the person behaves in the same way in similar situations; and 3) Consistency: the extent to which the person behaves like this every time the situation occurs.

This study was conducted to determine the factors associated with success in the Certified Public Accountant Licensure Examination of the accountancy graduates of the Rizal Technology University, covering May 2012 and October 2012 CPA board examinations. Specifically, the study sought to find answers to the following research questions:

1. What is the demographic profile of the accountancy graduate-respondents by the following characteristics?
1.1 Gender
1.2 Age Group
1.3 Monthly Income
1.4 Scholarship
1.5 CPA Board Rating
1.6 CPA Board Passer/Non-Board Passer
1.7 Grade Weighted Average (GWA)

2. To what extent do the following factors influence the CPA examination performance as perceived by the accountancy graduate respondents?

\subsection{Student Factor \\ 2.2 Home and Family Factor \\ 2.3 School Factor}

3. What is the relationship between the accountancy graduates' demographic profile and their CPA board performance?

4. What is the relationship between attendance to review courses and the performance of the accountancy graduate respondents in the CPA licensure examination?

5. How may the CPA licensure examination performance be improved as viewed by the accountancy graduate respondents? 


\section{METHODOLOGY}

This study utilized the descriptive research method because of its appropriateness to the problem. This method involves collecting data in order to answer questions concerning the current status or trend about the phenomenon (Gay, 2012). In this study, the method looked into status or trends about factors associated with success in the Certified Public Accountant board examination.

The survey and the correlational designs of descriptive research were used. Survey design was used to examine current conditions or status of the population with respect to demographic profile; perceptions on student, home and family, and student factors that may influence performance in the CPA licensure examination, and enhancement of licensure examination performance. The correlational design, on the other hand, delved into the relationships of demographic profile and attendance in review courses with the CPA board examination performance of the Accounting graduates of the Rizal Technological University. Documentary analysis technique was also used to establish the month and year the examinees took the Board exam and to look into their CPA board ratings.

The respondents of the study included 24 graduates of Bachelor of Science in Accountancy from the College of Business and Entrepreneurial Technology of the Rizal Technological University who took the CPA licensure administered by the Board of Accountancy of the Professional Regulatory Commission in May 2012 and October 2012. The graduates were purposively selected as respondents of the study. These respondents were chosen for a particular purpose. They constituted the group believed to have firsthand and adequate knowledge about the subject of the investigation (Leedy and Ormrod, 2010).

A researcher-made questionnaire was used to gather the data for the study. Part I elicits information about the demographic profile characteristics of the respondents that include sex, age, monthly, income, scholarship, grade weighted average, board rating, and licensure examination performance. Part II measures behaviors as to factors that contributed to passing the CPA board examinations such as student factors, home and family factors, school factors, attendance to review courses, time spent for CPA exam preparation, and recommendations by the examinees to further improve the CPA board results.

The study used the table of specifications in the preparation of the researcher-made instrument. This validation process was used to ensure that all items that were included in the questionnaire would answer the research questions posited in the study. The services of some experts were also tapped to review the instrument and forward their comments and suggestions for improvements. Their suggestions were consolidated and were used to improve the instruments. The questionnaire was then finalized for the dry-run. The questionnaire was pretested to a group of 14 CPA passers. These respondents were not included In the final administration of the instrument. The items were then analyzed and were correspondingly improved to eliminate vague items. The questionnaire was then finalized and, upon approval by the adviser, administered to the 24 subjects of the study. The CBET enrolment data and the PRC report on the CPA licensure examination results for year 2012 were also used in this study.

The study used the following formulas to quantitatively analyze the data:

1. Frequency. Through a frequency distribution table, the frequencies of the respondents' answers were tailed per response (i.e. gender: male, female) and thus represent the respondents on each factor (Fraenkel and Wallen, 2008).

2. Percentage. The relative percentage of each type of response per category is derived by this formula: (Fraenkel and Wallen, 2008). $\%=\mathrm{f} \mathrm{i} / \mathrm{N}$ 
Where:

$\mathrm{f}_{\mathrm{i}}=$ frequency of responses per category/demographic

$\mathrm{N}=$ total number of scores/responses

Percentage is an index of relative position indicating the percentage of scores that fall at or below a given score.

3. Rank.Refers to the arrangement of data according to some criterion such as highest to lowest, biggest to smallest or best to worst. The highest item is given a rank of 1 , and the second item is given a rank of 2 and so on. (Levin and Fox, 2006).

\section{Weighted Mean}

A weighted mean is a value that is derived by dividing the sum of a set of responses by the number of responses. The mean is used in sub problem 2-3. The mean is calculated by the following formula. (Levin and Fox, 2006):

$$
\overline{\mathbf{X}}_{\mathbf{w}}=\frac{\sum \text { Ngroup Xgroup }}{\mathbf{N} \text { total }}
$$

Where:

$\overline{\mathbf{X}_{1}}=$ mean of a particular group

Ngroup = number in particular group

$\mathbf{N}$ total $=$ number in all group combined

$\overline{\mathbf{X}}_{\mathbf{w}}=$ weighted mean

5. Pearson r. To find out the relationships of each factor towards GWA and Board Rating, a Pearson's Product - moment Correlation Coefficient (Pearson's r) is employed and is shown on correlation matrices at the appendices. The formula for the Pearson's $r$ is as follows (Fraenkel and Wallen, 2008).

Pearson's r:

$$
\mathrm{r}=\frac{\mathrm{n} \Sigma \mathrm{xy}-(\Sigma \mathrm{x})(\Sigma \mathrm{y})}{\left.\sqrt{\left[\mathrm{n} \Sigma \mathrm{x} 2 \cdot(\Sigma \mathrm{x})^{2}\right.} 2\right]\left[\mathrm{n} \Sigma \mathrm{y} 2 \cdot(\Sigma \mathrm{y})^{2}\right.}
$$

Where:

$\mathrm{n}=$ number of paired responses

$\Sigma y=$ sum of responses for first variable

$\Sigma x y=$ sum of responses for second variable

$\Sigma \mathrm{x}^{2}=$ squared sum of the responses for the first variable

$\Sigma \mathrm{x}^{3}=$ squared sum of the responses for the second variable

Pearson $\mathrm{r}$ is an index of correlation appropriate when the data represent either interval or ratio scales, it takes into account each and every score and produces a coefficient between 100 and 100 .

\section{RESULTS AND DISCUSSION}

\section{Demographic Profile of the Accounting Graduate Respondents}

Majority (more than 50.0\%) of the accounting graduate respondents were females, aged 23-25 years, with monthly income of $\mathrm{P} 10,000$ or more, with academic or non-academic scholarship, CPA board passers, with board ratings of 75 or higher, and with grade weighed averages of 1.50 to 2.00 . 
Previous studies have shown grade GWA to be a significant factor in predicting CPA exam success. Candidates with higher grades have greater success on the CPA exam. Perhaps this can be attributed to grade inflation. As Dunn and Hall (2009) commented, ". . one would expect a priori that lesser quality candidates would tend to represent a relatively larger proportion of repeat candidates", and that the CPA exam is basically a textbook exam. Repeat candidates who have lower grades are expected as a group to do less well on subsequent exams. (Titard and Russel, 2009).

\section{Extent of Influence of the Following Factors on CPA Examination Performance as Perceived by the Respondents}

2.1 Student Factors. As shown by the mean scores of 3.71 to 4.46, accountancy graduate respondents perceived the following factors to have high influence on their performance in the CPA licensure examination: interest in the course, time spent in studying lessons in preparing assignments, doing research in the library or through Internet, active participation in review sessions conducted by the University, active participation in review sessions conducted by a review school, and number of hours spent in reading books and materials related to accountancy.

2.2 Home and Family Factors. The mean scores of 3.46 to 4.50 showed that the Accountancy graduate respondents perceived the following factors to have high influence on their performance in the CPA licensure examination: family supports all expenses, parents help a lot in student's studies, family gives motivation and encouragement; family gives motivation and encouragement, family can be depended upon when problem arises; family provides healthy food, family supports extracurricular activities; parents provide advice in activities or goals the student wants to accomplish; and student's presence is acknowledge in every family activity.

2.3 School Factors. The means of 2.68 to 3.35 indicated that the accounting graduate respondents perceived the following factors to have average influence on their performance in the CPA licensure examination: adequacy of technology hardware and software, adequacy laboratories and physical facilities; adequacy of laboratory equipment, supplies and materials; adequacy of audio visual resources; adequacy of sports and recreational facilities; availability of good accounting programs; and availability of good accountancy faculty and staff. Easy access to transportation showed high influence with a mean of 4.13 .

\section{Relationship between Demographic Profile and CPA Board Performance of the Respondents}

The Pearson r values of .592 and -.768 with corresponding Pearson chi-square values of 19.729 and 30.575 respectively in scholarship vs. board ratings and general weighted average vs. board ratings were found to be significant at Alpha .05 under the degree of freedom of 22 . The other pairs were not significant. The results failed to reject the declarative hypothesis.

\section{Relationship between Review Courses and CPA Board Ratings of the Respondents}

The obtained Pearson $r$ and Coefficient of Determination values of $r 1.00$ and $r^{2} 79.0 \%$ in College Review and $r .899$ and $r^{2} 79.0 \%$ Revision School were highly significant at Alpha .05 under df of 22 and 16 respectively. The results failed to reject the declarative hypothesis.

The foregoing results indicate that the review classes provided in the accountancy curriculum of the University are beneficial factors that influence students' performance in the CPA board exams. Attendance to review courses conducted by review schools also help the students pass the examination The findings from the qualitative research revealed that interviewees have recognized the importance of pre-board or mock board administered by the university and review school. Many interviewees considered it as a tool for preparation in the actual board examination. Some said "it is a study-habit forming as one will be trained to study harder in preparation for the pre-board or mock examination. They also added that "it helps boost our confidence level in taking the actual board examinations because we have been used to it through the pre-board or mock board exams we have 
undergone since we were in first year college." Another interviewee commented that the pre-board or mock board practice must be continued because it is the best way of gauging capability of the students in taking the board examination, which was also observed by Sagarino and Corpuz, 2011. One of the tips recommended to pass the CPA board exam in the Philippines is to have a thorough review. It is recommended that students must take seriously the review courses required in the curriculum and to enroll in a reputable review center to have a deeper understanding of the actual board exam. Review schools have the updated materials and event regarding what is latest in the board. They assist students for their CPA exam schedule and requirements to ensure that students are in the right tracts.

\section{How the CPA licensure Examination may be improved as viewed by the respondents}

Majority of the accountancy graduate respondents perceived that the CPA licensure examination performance can be improved through continuous improvement of the accountancy program (22 or $91.67 \%$ ), enhancement of the University's review program (20 or $83.33 \%$ ), improvement and strict observation of the entry requirements for accountancy program; and leveling the difficulty of pre-board/mock board examinations with that of the CPA board examination (14 or $58.33 \%$ ).

\section{CONCLUSIONS}

The following conclusions were drawn from the findings of the study:

1. The accountancy graduates or examinees are predominantly female, young in age, coming from families with low monthly income, with scholarship, with good grade weighted average, and with review courses handled by the University and prestigious CPA review schools.

2. The student factors and home family factors highly influence performance in the CPA licensure examinations while the school factors are seen to have average influence.

3. Statistical data show that the accountancy graduates' profile in terms of gender, age group, and monthly income failed to show significant relationships with their CPA board ratings

4. Student scholarship (academic or non-academic), grade weighted averages, and attendance to review courses handled by prestigious review schools are positive factors in passing the CPA licensure examination.

5. As advocated by the accountancy graduates or examinees, the CPA Licensure examination performance can be enhanced through continuous improvement of the accountancy program, strengthening the University review courses, improved and strict observation of entry requirements for accounting program, and leveling of pre-board/mock board examinations with actual CPA examination.

\section{RECOMMENDATIONS}

1. There is a need for the University to consider the factors found to have influence over the performance in the CPA licensure examination. This may help in the continuous review and enrichment of the B.S. Accountancy curriculum to make it responsive and relevant to the needs of the time.

2. The successful candidate's success is significantly related to the extent to which his review program is organized. This requires hard work and commitment. Space must be created to accommodate a successful review. In attending review courses, passing the CPA exam must be the foremost objective fixed in the mind's eye, during the months preceding the examination. The arrangements necessary to allow for hours that must be set aside for review are usually made by forgetting all nonessential personal and social activities during the review period.

3. There are several CPA review manuals that provide assistance to candidates in the form of study outlines and past exam questions and answers. Such manuals are most useful when they are 
supplemental to, or part of a classroom CPA review course. Printed materials generally need instructors to illuminate them and to guide the candidate through.

4. To become a successful candidate, it is not enough to know the CPA areas of specialization. The candidate must be familiar with exam format, anticipate exam content, dealing with the unexpected, budgeting your time, and working efficiently. The CPA exam requires study skills, test-taking skills, and attributes necessary for the CPA examination. Successful candidates are prepared, confident, self-disciplined, and motivated.

5. Regular assessment through qualifying examination is recommended to improve performance. Grades of the students should be strictly monitored for strict implementation of retention policy.

6. The pre-board/mock board examinations in the review courses should be strengthened to match the of test questions in the actual CPA licensure examination. Some of the best ways of developing examination skills include familiarity with examination format and time management skills.

7. Other variables not taken in this study could be examined as a recommendation for further studies to explore their relationships with candidates' performance in the CPA board examination.

\section{References:}

[1] Bala, J., The Naked Truth About CPA Examination, Graduate Research Journal, University of the East. 2008.

[2] Abrugar, V., The Accountancy Profession in the Philippines and the Philippines Institute of Certified Public Accountants (PICPA). Accountants' Journal. 2009, Vol. 44 : 12-17.

[3] Annual Reports (2011-2014), Rizal Technological University. Mandaluyong City, Philippines.

[4] Hunt, S., Integration and attribution theories in personality impression formation., J. Pers. Soc. Psychol., 2009, 52:345-48.

[5] Jones, E. and K.E. Davis. From acts to disposition: The attribution process in person perception, Adu. Exp. Soc. Psychol. 2005, 2:219.

[6] Kelly, H.H., Attribution Theory in Social Psychology, Nebr. Symp. Motiv. 2007, 15:192-238.

[7] Gay, L.R., Educational Research: Competencies for Analysis and Application. $6^{\text {th }}$ Edition. Upper Saddle River, New Jersey: Prentice Hall International. 2012.

[8] Leedy, Paul D. and Jeanne Ellis Ormrod, Practical Research: Planning and Design. $8^{\text {th }}$ Edition. Upper Saddle River, New Jersey: Merill Prentice Hall, 2010.

[9] Fraenkel, Jack R. and Norman E. Wallen, How to Design and Evaluate Research in Education. Seventh Edition. Boston: McGraw-Hill, Higher Education, 2008.

[10] Levin, Jack and James Alan Fox , Elementary Statistics in Social Research. Tenth Edition. Boston: Pearson Foundation, Inc., 2006

[11] Dunn, W.T. and F. Hall. "Effects of overall academic record on CPA examination performance. Journal of Accountancy, May 2009. pp. 24-29.

[12] Titard, Pierre L. and Keith Russel. Factors affecting CPA examination success. Accounting Horizons. September, 2009.

[13] Sagarino, Emma V. and Deogarcia B. Corpuz. "Correlates of Certified Public Accountant (CPA) examination: An analysis of five-year performance.” UIC Research Journal, 2011, 17 (2), 129-140. 